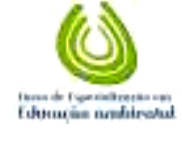

MACHADO \& MULLER, vol.(4), n4, p. 749-757, 2011. Monografias Ambientais

(e-ISSN: 2236-1308)

REMOA

\title{
CAMINHADA NA NATUREZA: PRÁTICA ALTERNATIVA DE EDUCAÇÃO FÍSICA ESCOLAR PARA FINS DE EDUCAÇÃO AMBIENTAL
}

\author{
Machado, P. R. M. ${ }^{2}$, Muller, C. A. ${ }^{2}$ \\ Prof. Adjunto, DEM/CT/UFSM, Orientador, Curso de Especialização em Educação Ambiental. \\ ${ }^{2}$ Pós-Graduando Curso de Especialização em Educação Ambiental UFSM. Artigo extrato de monografia.
}

\section{RESUMO}

A educação ambiental busca a sua comunhão com os princípios fundamentais de participação, cidadania, autonomia e sustentabilidade almejando uma educação que priorize, em suas bases epistemológicas e metodológicas, a formação de homens aptos a enfrentar os desafios sócio-ambientais que na maioria dos casos são produtos de sua própria ação. São vários os caminhos para promoção da educação ambiental na sociedade e dentro da escola não é diferente. Em concordância com os parâmetros curriculares, a educação ambiental deve permear o currículo de todas as disciplinas e, assim, a educação física também tem como dever a exploração deste tema. Para isso, procurou-se neste trabalho, como forma de lecionar- se a educação ambiental dentro da disciplina de educação física, promover e estimular a caminhada na natureza. Durante a pesquisa buscou-se identificar as especificidades que estão sendo trabalhadas na área de educação ambiental e a forma como é vista a educação física, com a menção das possibilidades dessa disciplina diferenciada que pode favorecer a aprendizagem e fixação de diversos conteúdos. Especificamente, neste trabalho, tratou-se da educação ambiental e o seu possível relacionamento com a educação física como forma de complemento de uma para a outra ao utilizar-se a caminhada na natureza. Dentro desta perspectiva foi investigada o quão efetiva pode se tornar a atividade e os possíveis benefícios da mesma. Para a realização da pesquisa foram selecionadas duas turmas de escolas distintas, onde uma realizava a atividade da caminhada e a outra não. As duas turmas foram submetidas a questionários com temas relacionados ao meio ambiente e, sendo após, realizada uma comparação para avaliar-se percepção das questões ambientais entre as duas turmas. Foi possível concluir que a caminhada na natureza é efetiva como meio instrutivo de educação ambiental, apesar de observar-se que, em relação à percepção ambiental, os alunos das duas turmas tiveram visões semelhantes. Porém, no quesito comportamental sobre o meio ambiente a turma que realizou a atividade apresentou resultados mais significativos.

\footnotetext{
ABSTRACT

Environmental education seeks a communion with the fundamental principles of participation, citizenship, autonomy and sustainability, aiming for education that, in its epistemological and methodological principles, gives priority to shaping people who are qualified to face the social-environmental challenges which, in many cases, are a product of their own action. There are several ways of promoting environmental education within society, and it is no different at school. According to curricular parameters, environmental
} 
education should permeate the curriculum of all school subjects; therefore Physical Education also has the duty of looking into this topic. In order to achieve that purpose, this work sought to teach environmental education within physical education by promoting nature walks. The work endeavored to identify the specificities carried out in environmental education and the way that physical education is seen, mentioning the possibilities of this particular school subject that aid in the learning of certain contents: in this specific case environmental education and its possible relationship with physical education as a manner of complementing one other by means of nature walks. Within this perspective, this work investigates the effectiveness of this activity and its possible benefits. In order to conduct this research two class groups were chosen from different schools, one of which carried out the nature walk activity whereas the other did not. Both groups were given a questionnaire with topics related to the environment, and a comparison was made of the perception of environmental questions between the two. It was possible to infer that nature walks are an effective method of teaching environmental education: despite observing that, as far as environmental awareness is concerned, students from both groups had similar views, in the behavioral question regarding environment, the class that undertook the proposed activity presented more significant results.

\section{INTRODUÇÃO}

O conceito de educação ambiental evoluiu ao longo do tempo. Historicamente esteve ligado aos conceitos ou representações que se atribuíram ao meio ambiente. Nas últimas décadas vem consolidando-se para tornar-se um parâmetro no estabelecimento de um outro pensar a educação no seu conjunto, haja vista, o número de publicações, projetos, experiências e pessoas envolvidas com a temática em todas as esferas.

Segundo Guimarães apud Soares (1995) a educação ambiental tem o importante papel de facilitar a percepção da integração do homem com o meio ambiente, de modo que esta seja uma relação de harmonia, consciente do equilíbrio dinâmico da natureza. A educação ambiental proporciona, por meio de novos conhecimentos, atitudes e valores, a inserção de educando e educador, enquanto cidadãos, no processo de transformação do atual quadro ambiental de nosso planeta.

Para Dias (1994), a educação ambiental é um processo permanente no qual os indivíduos e a comunidade tomam consciência do seu meio ambiente e podem adquir conhecimentos, valores, habilidades, experiências e determinação que os tornem aptos a agir e resolver problemas ambientais presentes e futuros.

Na visão de Müller (2003), a educação ambiental é uma forma de prática educacional sintonizada com a vida em sociedade. Ela só pode ser efetiva se todos os membros da sociedade participarem, de acordo com suas habilidades, das complexas e múltiplas tarefas de melhora das relações das pessoas com seu meio ambiente. Isto só pode ser alcançado se as pessoas se conscientizarem da necessidade de seu envolvimento e de suas responsabilidades. $O$ trabalho da educação ambiental deve ajudar os educandos a construírem uma consciência global das questões relativas ao ambiente, para que possam assumir posições afinadas com os valores referentes à sua proteção e melhoria de condições de vida. Para isso, é importante que se atribua significado àquilo que se aprende sobre as questões ambientais, resultado da ligação que se estabelece entre o que se aprende e a sua realidade cotidiana, possibilitando a utilização destes conhecimentos em outras situações. 
De acordo com os Parâmetros Curriculares Nacionais (Brasil, 1998), o objetivo do trabalho com o tema meio ambiente é contribuir para a formação de cidadãos conscientes, aptos para decidirem e atuarem na realidade sócio-ambiental de um modo comprometido com a vida, com o bem estar de cada um e da sociedade, local e global. Para isso, é necessário que, mais do que informações e conceitos, a escola se proponha a trabalhar com as atitudes e com a formação dos valores.

A Política Nacional de Educação Ambiental (Brasil, 1999) traz em seus princípios o pluralismo de idéias e concepções pedagógicas, na perspectiva da interdisciplinaridade. Esta lei determina que a educação ambiental não seja trabalhada na forma de disciplina específica, mas que permeie o currículo de diversas disciplinas. Para tal, é de fundamental importância a sensibilização dos docentes da rede pública de ensino, para a necessidade do seu engajamento no processo de produção e/ou de construção de novas práticas pedagógicas mediadas pela educação ambiental.

Uma alternativa de trabalho que vem se expandindo é a caminhada na natureza, que é geralmente realizada nas aulas de educação física. Então, fica a expectativa da sua real efetivação no que se refere à educação ambiental. Nesse sentido, esta pesquisa pretendeu investigar se a atividade realmente traz mudanças de consciência, sobre as ações de preservação ambiental, dos alunos participantes.

\section{REVISÃO BIBLIOGRÁFICA Educação ambiental}

A necessidade de abordar o tema da complexidade ambiental decorre da percepção sobre o incipiente processo de reflexão acerca das práticas existentes e das múltiplas possibilidades de, ao pensar a realidades de modo complexo, defini-la como uma nova racionalidade e um espaço onde se articulam a natureza, técnica e cultura. Refletir sobre a complexidade ambiental abre uma estimulante oportunidade para compreender a gestação de novos atores sociais que se mobilizam para a apropriação da natureza, para um processo educativo articulado e compromissado com a sustentabilidade e a participação, apoiado numa lógica que privilegia o diálogo e a interdependência de diferentes áreas de saber. Mas também questiona valores e premissas que norteiam as práticas sociais prevalecentes, implicando mudança na forma de pensar e transformação no conhecimento e nas práticas educativas (JACOBI, 2003).

Segundo Reigota (1998) apud Jacobi (2003), a educação ambiental aponta para propostas pedagógicas centradas na conscientização, mudança de comportamento, desenvolvimento de competências, capacidade de avaliação e participação dos educandos. Para Pádua \& Tabanez (1998) apud Jacobi (2003) a educação ambiental proporciona o aumento de conhecimentos, mudança de valores e aperfeiçoamento de habilidades, condições básicas para estimular uma maior integração e harmonia dos indivíduos com o meio ambiente. $\mathrm{E}$, de acordo com Guimarães (2000) apud Vargas \& Tavares (2004) a educação ambiental é transformadora de valores e atitudes através da construção de novos hábitos e conhecimentos, criando uma nova ética, sensibilizadora e conscientizadora no processo relacional.

Conforme Reigota (1994, 2001), Loureiro (2002) e Loureiro (2000) apud Guimarães et all (2007), a educação ambiental é uma educação que se expressa com as seguintes características: 
a) É uma educação política, no sentido de que ela reivindica e prepara os cidadãos para exigir justiça social, cidadania e ética nas relações sociais e com a natureza;

b) É uma crítica aos modelos autoritários, tecnocráticos e populistas que não levam em conta alternativas sociais baseadas em princípios ecológicos, éticos, e justos com as gerações atuais e futuras;

c) É uma educação social que tem por finalidade a construção de valores, conceitos, habilidades e atitudes que possibilitem o entendimento da realidade de vida e a atuação responsável dos atores sociais, individuais e coletivos, no ambiente;

d) É um elemento estratégico na formação da consciência crítica das relações sociais e de produção que situam a inserção humana na natureza.

O meio ambiente possui um atributo totalmente interdisciplinar, ratificando sua importância no processo educacional. A compreensão dessa temática e a construção de novos valores e atitudes são princípios básicos da educação ambiental, portanto, indispensável no ensino formal. A educação ambiental deve oferecer um programa, cuja finalidade seja a tomada de consciência por parte dos cidadãos, a formulação de novos valores e conceitos, e a promoção de uma nova visão e exercício da cidadania. Levar-se em consideração as expectativas e as esperanças dos alunos é, com certeza, o melhor caminho para se chegar a um ensino de qualidade (LUCENTINI, 2005).

Conforme Reigota (2001) apud Lucentini (2005) a educação ambiental é uma das mais importantes exigências educacionais contemporâneas, não só no Brasil, mas também no mundo. Deve ser ainda considerada como uma grande contribuição filosófica e metodológica à educação geral

\section{Educação física}

O debate em torno da especificidade da educação física escolar vem amadurecendo desde a década de oitenta, período em que novas propostas foram elaboradas com vistas à superação do modelo tradicional de ensino. Conforme Rodrigues \& Darido (2006) apud Leite a Hartmann (s.d.), até os dias atuais, várias foram as reflexões e proposições realizadas na área de educação física em busca de uma identidade.

Mas, apesar disso, o que se pode observar na maioria dos casos, inclusive na educação física, são aulas baseadas em modelos esportivistas e recreacionistas, nos quais o professor desenvolve os quatro esportes tradicionais (futsal, handebol, voleibol e basquete) ou no segundo caso, entrega uma bola aos alunos se eximindo do ato educativo. Outro fato a destacar-se é que, comumente, a prática de atividades físicas não é vista como um espaço para a aprendizagem, isso acontece porque foi constituída uma idéia de que só é possível aprender quando o individuo dedica-se por horas a leitura nos livros (COIMBRA apud LEITE \& HARTMANN, 2006).

Sobre essa temática, existe a contribuição de Vargas \& Tavares (2004) que afirmam que a educação física, enquanto orientada nos moldes do esporte de alto nível, coloca o aluno mais como objeto do que como sujeito e como individuo. Além disso, as aulas nem sequer motivam ou preparam o aluno para efetuar, em seu tempo livre, uma prática esportiva que se reflita por toda a vida (DIECKERT, KURZ e BRODTMANN, 1985 apud VARGAS \& TAVARES, 2004).

Com a educação física, ao aplicarem-se seus conteúdos em atividades variadas e pautadas em propostas transversais, os professores podem atender as expectativas dos alunos, oferecendo um conhecimento que irá além do conhecimento de habilidades motoras. De acordo com 

relevância social, como por exemplo, a educação ambiental, os professores de educação física podem contribuir para o distanciamento do aluno em relação à sua disciplina. Ao problematizar,fundamentar, e interrelacionar as mais variadas dimensões pode-se proporcionar aos alunos conhecimentos significativos, abandonando-se o simples fazer por fazer. Esse deve ser um dos principais papéis do professor de educação física enquanto educador.

\section{Educação física e educação ambiental}

A educação ambiental é atravessada por vários campos de conhecimento, o que a situa como uma abordagem multirreferencial (JACOBI, 2003). Ainda sobre educação ambiental, Tristão (2002) apud Jacobi (2003) menciona que os campos de conhecimento, as noções e conceitos podem ser originários de várias áreas do saber.

Tanto é que o meio ambiente não é responsabilidade somente das ciências naturais, pois seu enfoque é interdisciplinar além de multidisciplinar (NEGRIN PÉREZ e TORRES VÁSQUEZ, 2000, apud VARGAS \& TAVARES, 2004). Sendo assim, a educação física também tem um importante papel na produção de educação ambiental.

Segundo Lucentini (2005), a educação física apresenta subsídios suficientes para abordar e relacionar a temática ambiental, contribuindo ainda mais para formação e o exercício da cidadania do educando, podendo integrar e relacionar conteúdos específicos com temas variados de relevância social. Afirma ainda que, relacionar a temática ambiental na prática de educação física talvez não seja tarefa muito simples, mas também não é impossível, pois algumas atividades apresentadas pelos professores, com algumas alterações, podem abordar assuntos referentes ao meio ambiente.

Os pressupostos que fundamentam uma educação física como um paradigma ambientalizado no meio escolar para fins de consecução da investigação estão alicerçado nas proposições de que ao identificar o aluno com seu meio natural, a educação física permite formar conviç̧ões meio ambientais, o desfrute nos alunos pela descoberta de suas possibilidades na preservação do meio natural, a compreensão e aprendizagem de conceitos meio ambientais relacionados com a educação física, torna a atividade mais dinâmicas e prazerosas, o trabalho no espaço natural provoca uma disposição positiva acerca da natureza e as relações interpessoais e de grupo encontram-se favorecidas (NEGRIN PÉREZ e TORRES VÁSQUEZ, 2000 apud VARGAS \& TAVARES, 2004).

Por realizarem-se em sua maioria ao ar livre, as atividades pertinentes à educação física, se configuram como um ótimo momento para a formação de conviç̧ões meio ambientais e proteção do meio ambiente. Além disso, o contato direto com o meio natural e seus objetivos, baseados na eliminação do estresse e da sobrecarga intelectual além da manutenção da qualidade de vida, coloca a possibilidade do trabalho de uma educação ambiental (VARGAS \& TAVARES, 2004). A intensificação de uma aproximação qualitativa dos seres humanos ao meio ambiente natural pode acelerar esse processo, tornando eficiente o sonho de harmonia e, nos espaços institucionais, como escola, esta pode representar uma perspectiva excelente para a reflexão de valores dessa relação (MARINHO E SCHWARTZ,

2005). 
Barros (2000) apud Marinho \& Schwartz (2005), trata da importância da área de educação física no tratamento da educação ambiental, aqui entendida como processo de aprendizagem permanente, baseado no respeito a todas as formas de vida. Tal educação afirma valores e ações que contribuem para a transformação humana e social e para a preservação ecológica. A educação física se torna disciplina privilegiada para o trato da educação ambiental de maneira que o fato de ser uma disciplina baseada principalmente em experiências práticas e vivências pessoais, facilita o desenvolvimento de questões ambientais, segundo Pastor \& Pastor (1997) apud Marinho \& Schwartz (2005).

Lembrando que o estudo da educação ambiental deve proporcionar um novo olhar, tanto para o meio ambiente, como para o próprio homem, uma reestruturação de conceitos, uma maneira nova de pensar e agir em relação ao meio, e segundo Lucentini (s.d.) a educação física permite um campo de atuação nessa área, principalmente levando-se em conta os esportes de aventura praticados na natureza.

\section{Caminhada na natureza}

A caminhada na natureza, mais conhecida como tracking, é uma atividade de aventura que segundo Marinho \& Schwartz (2005) está em pleno crescimento e que, de acordo com Guimarães et al (2007), constantemente estão se criando cada vez mais novas modalidades esportivas nessa área.

Com isso, fica evidente ser esse um campo com enormes possibilidades de ação e atuação para o desenvolvimento de uma consciência crítica a respeito do meio ambiente. Sua realização é tão simples que há a necessidade apenas de motivação para iniciá-la, pois a caminhada em si não necessita de um condicionamento aprimorado do praticante em relação às outras atividades de aventura, como ciclismo, montanhismo e escalada.

A caminhada na natureza, nada mais é que o caminhar do indivíduo dentro de um ambiente natural constituído por árvores, matas, fauna, rios ou riachos. Em geral, quem pratica essa atividade busca sentir-se parte daquilo que vê e necessita interagir e admirar as belezas a sua volta, além de desfrutar da calma e da paz transmitida por este ambiente.

Este tipo de atividade, pelas vivências experimentadas e ligação direta com a natureza, tornou-se uma possibilidade de atividade da educação ambiental efetiva, que segundo Marinho (2004) apud Guimarães et al (2007), ao contribuir para o despertar da sensibilidade e a responsabilidade ambiental coletiva, impulsiona o estabelecimento de políticas ambientais em níveis local e global. Não obstante, a tomada de consciência da dependência da natureza para a realização dessas atividades, sem dúvida, irá gerar a compreensão da importância da preservação do meio ambiente.

A caminhada tem por objetivo trabalhar a educação ambiental integralmente e não apenas, tal como a maioria das atividades nas escolas segundo Bortolozzi \& Perez Filho (2000), buscar-se algumas soluções técnicas conservacionistas, pensando-se em resolver de forma simplista, problemas ambientais complexos. Entre outras se destacam: reposição de matas ciliares, coleta seletiva do lixo, reciclagem do lixo, assoreamento dos rios, plantio de árvores, e outras, revelando uma visão naturalística, portanto reducionista dos problemas, sem uma contextualização histórica espacial desses problemas, ignorando completamente uma discussão com os alunos sobre as causas. 
O potencial educativo dessa atividade, como indicam Monteiro \& Pereira (1995) apud Marinho \& Scwartz (2005), parece ser muito extenso, principalmente porque facilita situações educativas em experiências pouco habituais para os participantes, possuindo um forte caráter motivador, carregadas de emoção, de significados e de intenção. Os autores ainda mencionam que, pelo exercício das atividades de aventura, onde se inclui a caminhada na natureza, "abre- se um caminho para o desenvolvimento da conscientização ambiental".

Contribuindo ainda sobre essa temática Bahia (2005) apud Lucentini (2006), as experiências vividas por meio de tais práticas podem ser uma oportunidade para o surgimento de novas atitudes e sentimentos, podendo unir vivências corporais e o respeito pelo meio ambiente. Assim, as atividades desempenhadas na natureza, como a caminhada na natureza, podem contribuir para o desenvolvimento do bem estar físico e mental dos indivíduos que as praticam, com o objetivo de contribuir na preservação da natureza, sem esquecer-se da melhoria da qualidade de vida harmoniosamente pelo lazer e pela conscientização sobre os problemas ambientais presentes atualmente (SILVA, 2007).

\section{MATERIAIS E METODOLOGIA}

Neste trabalho de pesquisa, foi utilizada uma trilha ecológica existente na Escola Municipal de Ensino Fundamental (EMEF) 21 de Abril da cidade de Panambí-RS, localizada no interior do município. A trilha, localizada nas dependências territoriais da escola, passa pela mata ainda preservada nos arredores da região e tem aproximadamente 3,0 km (três quilômetros) de extensão. Existem trechos nos quais é necessário fazer uma incursão no arroio existente e que, em determinados pontos, a trilha acompanha o seu leito.

A pesquisa envolveu alunos de 5ạ e 6á séries de duas escolas, com idades entre onze e treze anos. Uma das turmas utilizadas foi da Escola Municipal de Ensino Fundamental 21 de Abril, onde encontra-se a trilha, constituída por poucos alunos e que está localizada na zona rural. Outra escola que colaborou com o estudo disponibilizando uma turma de alunos, foi a Escola Municipal de Ensino Fundamental Conrado Doeth, também da cidade de Panambí, RS e localizada na zona rural do município. Esta, composta por poucos alunos e que nunca realizaram uma trilha ecológica em atividades de educação física.

Para avaliação da percepção dos alunos em relação às questões ambientais foram utilizados dois questionários com perguntas abertas e de cunho ambiental, tratando da preservação e do relacionamento do homem com o meio ambiente. O primeiro questionário foi voltado ao grupo de alunos da Escola Municipal de Ensino Fundamental 21 Abril, que foi caracterizada no trabalho como sendo a Turma A. O outro questionário foi voltado para o grupo de alunos da Escola Municipal de Ensino Fundamental Conrado Doeth e foi caracterizado no trabalho como sendo a Turma B.

Os questionários se distinguiam apenas nas questões finais, onde no questionário voltado para a Turma A, que realizou atividades de caminhada na natureza, as questões mencionadas tiveram uma abordagem direta com a trilha ecológica e na Turma $B$ as questões finais partiram para uma abordagem indireta, sem mencionar a prática de uma caminhada em uma trilha. Com a Turma A foi realizada a caminhada na trilha ecológica de maneira a oportunizar que os alunos vislumbrassem as diferentes facetas que podiam ser visíveis durante a atividade e que, na seqüência, faziam-se explicações buscando uma conscientização acerca das situações encontradas. 
Também foram abordados assuntos voltados às questões ambientais e à natureza, como as queimadas, a poluição e reciclagem de materiais. Após as atividades terem sido realizadas foi proposta a aplicação do questionário para avaliação da eficácia da atividade como veículo de educação ambiental.

Quanto à Turma B, que nunca realizou a atividade, o questionário foi aplicado apenas para verificar quais eram as percepções dos alunos acerca das questões ambientais, possibilitando mais tarde confrontar os dados obtidos com os questionários da Turma $\mathrm{A}$. Através das respostas também se buscou identificar os benefícios e a efetividade da caminhada na natureza no que se refere à educação ambiental.

\section{RESULTADOS E DISCUSSÕES}

Com a metodologia utilizada (que mostrou-se foi satisfatória), possibilitou a avaliação da possível eficiência da caminhada na natureza em aulas de educação física como agente de educação ambiental.

Através da análise dos questionários propostos aos alunos participantes foram constatados diferenças de percepções ambientais entre as duas turmas. Sendo na Turma A, que realizou caminhada na natureza nas aulas de educação física, encontrando respostas de maior conhecimento ambiental e na Turma $B$, que não realizou caminhada na natureza nas aulas de educação física, encontrando respostas mais abstratas.

Considerando o número de alunos de cada turma que deram respostas positivamente sobre ações ambientais verificou-se que foi a Turma A que apresentou maior porcentagem. As questões com esse propósito discutiam sobre as diversas conseqüências para um determinado contexto ambiental e em seguida outra questão tratava das causas que ocasionavam as conseqüências e por final versava-se uma questão para saber se o aluno praticava determinada ação em prol ou não para o ambiente em relação aquele contexto.

A partir do questionário voltado para a Turma A identificou-se um benefício da atividade proposta na educação física, a qual se trata de incitação do aluno a conversar sobre educação ambiental com amigos e ou familiares, promovendo uma reflexão acerca do meio ambiente e disseminando-o.

\section{CONCLUSÕES}

Com a realização do trabalho concluiu-se que a caminhada na natureza, como prática alternativa de educação física escolar para fins de educação ambiental, é efetiva e esta pesquisa traz uma nova proposta de trabalho de educação ambiental dentro da disciplina de educação física, a qual proporciona ao docente uma ferramenta eficiente para se trabalhar o tema ambiental.

É importante enfatizar que um bom ponto de partida para amenizar os problemas existentes é começar a mudar os pensamentos e atitudes em relação ao meio ambiente, repensar a idéia de superioridade do homem em relação à natureza. E para isso, a educação física também é um viés para disseminar esses novos valores.

A situação do meio ambiente nos desafia a preservar e estabelecer a harmonia entre a natureza e o homem, para garantir um meio ambiente ecologicamente equilibrado e sadio; e, ao mesmo 
tempo, possibilitar um desenvolvimento social justo, permitindo que as sociedades humanas atinjam uma melhor qualidade de vida em todos os seus aspectos.

É preciso que haja uma transformação da educação geral, em todos os seus níveis e modalidades, uma educação mais comprometida com a construção da cidadania. A educação ambiental, neste aspecto, visa um aprofundamento de democracia e o fortalecimento de uma consciência e ética ecológica reforçando os sentidos dos valores, contribuindo e preocupando com o bem-estar geral, tanto nas presentes gerações quanto futuras. Apenas os seres humanos interferem na ordem, no equilíbrio e na evolução natural dos ecossistemas; então, somente a eles cabe minimizar os efeitos de suas ações.

\section{REFERÊNCIAS BIBLIOGRÁFICAS}

BORTOLOZZI, Arlêude; PEREZ FILHO, Archimedes. Diagnóstico da Educação Ambiental no Ensino de Geografia. In: Outros Temas: Cadernos de Pesquisa. n.109, São Paulo, mar. 2000.

BRASIL. Política Nacional de Educação Ambiental. Diário Oficial da União, Lei n 9.795, 27 abr. 1999.

. Secretaria de Educação Fundamental. Parâmetros Curriculares Nacionais - Temas

Transversais: Meio Ambiente. Brasília: SEF/MEC, 1998. Disponível em:

<http://portal.mec.gov.br/seb/arquivos/pdf/meioambiente.pdf>. Acesso em 10 fev. 2009. DIAS, G. F. Educação Ambiental: princípios e práticas. São Paulo: Gaia, 1994. GUIMARÃES, M. A dimensão ambiental na educação. Campinas, SP: Papirus, 1995.

GUIMARÃES, S. S. M., et al. Educação Física no Ensino Médio e as Discussões Sobre Meio Ambiente: Um Encontro Necessário. IN: Rev. Brás. Cienc. Esporte, Campinas, v. 28, n. 3, p.157-172, maio 2007.

JACOBI, Pedro. Educação ambiental, cidadania e sustentabilidade. In: Outros Temas: Cadernos de Pesquisa. n.118, São Paulo, mar. 2003.

LEITE, R. A. P; HARTMANN, Cassio. Educação Ambiental e as Atividades de Aventura na Natureza como Conteúdo da Educação Física Escolar no Ensino Fundamental. ISBN:

85-85253-69-X. Livro de Memórias do IV Congresso Científico Norte-nordeste - CONAFF. S.d.

LUCENTINI, Leandro. Educação Física no Ensino Médio: A Educação Física e o Meio Ambiente. $15^{\circ}$ Congresso de Iniciação Científica. v. 31, n. 2, p.285-299, maio/ago. 2005.

LUCENTINI, Leandro; SIMÕES, Regina. Educação Física no Ensino: A Educação Física e o Meio Ambiente. S.d. 6 pg.

MARINHO, Alcyane; SCHWARTZ, Gisele Maria. Atividades de Aventura como

Conteúdo da Educação Física: Reflexões Sobre seu Valor Educativo. <http://efdeportes.com.> Revista Digital - Buenos Aires. Ano 10. n.88. set. 2005. Acesso em 05 fev. 2009.

MÜLLER, Jackson. Educação ambiental: diretrizes para a prática pedagógica. Porto Alegre: FAMURS. 2003.

SILVA, P. P. C da. A Educação Física Interagindo com a Educação Ambiental na Inclusão do Deficiente Visual. S.d.

VARGAS, J. N. E de; TAVARES, F. J. P. A Educação Ambiental no contexto da Educação Física Escolar. <http://efdeportes.com. . Revista Digital - Buenos Aires. Ano 10. n.69. fev. 2004. Acesso em 05 fev. 2009. 